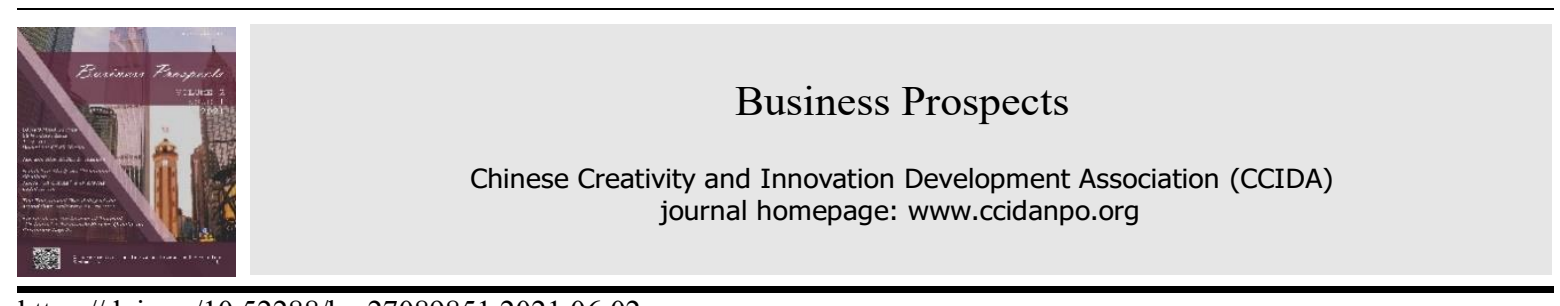

https://doi.org/10.52288/bp.27089851.2021.06.02

\title{
Risk Analysis and Countermeasures of Small Catering Companies Under COVID-19
}

\author{
Shao-Ru Cai ${ }^{1, *}$ \\ ${ }^{1}$ Lecturer of School of Management, Xiamen University Tan Kah Kee College \\ * Correspondence: caishr@xujc.com
}

Received: 2021.04.13; Accepted: 2021.04.30; Published: 2021.06.01

\begin{abstract}
The outbreak of COVID-19 in China at the beginning of 2020 has hit the catering companies hard. Many catering companies are facing the critical situation of large losses or even close down directly. Compared with large and medium-sized catering companies, the risk awareness and anti-risk ability of small catering companies are weaker. Their risk management is at a lower level and they do not pay much attention to risk prevention. By identifying and analyzing the risks faced by the small catering companies, this paper puts forward countermeasures and suggestions with the hope to provide some reference for the risk management of the small catering companies and to strengthen its risk prevention ability.
\end{abstract}

Keywords: Small Catering Companies; Risk Analyze; Risk Countermeasure

\section{The Definition and Characteristics of Small Catering Companies}

Entrepreneurship has become a trend. More and more individual businesses and small businesses have become the main force of the economic market. Small catering companies are the main representative of the "figure". The small catering companies studied in this paper refers to the individual businesses or small businesses engaged in catering service activities, whose operating area are no more than 150 square meters, or whose dining seats are no more than 75 . Small catering business forms include: restaurants, fast food restaurants, snack shops, beverage shops, pastry shops, student meals etc.

Compared with large and medium-sized catering enterprises, the small catering companies have the following characteristics:

(1) Small scale and small investment: They are relatively small economic units in terms of personnel scale, asset scale and operation scale. Usually they work as individual business. If they run several branches or chain stores, they register as a company.

(2) Basic management level: They are usually operated independently or managed by the family. The management mode is chaotic and lack of professional business management skills and experience.

(3) Lack of development funds and narrow financing channels: They have less free assets and normally lack of stable fund supply. They may be in deep water when encounter an emergency.

(4) The overall quality of employees is not high: Due to limited financial resources, there are basically no personnel training or only simple training. Their employees generally are lack of service awareness and only provide basic service.

\section{Risk Identification and Analysis}

Enterprise operation risk refers to the possibility that the actual future results of an enterprise differ from the original expected goals under the influence of various uncertain and uncontrollable factors in the internal and external environment in the process of business operation, which is simply uncertain for the future of an enterprise.

The owner and operator of small catering enterprises are usually the same person. They may not have the 
modern management consciousness and concept. They are weak in the links such as risk identification, risk prediction, risk tracking, risk monitoring and risk summary. The operation risks of small catering companies under COVID-19 can be divided into internal risks and external risks. The internal risks mainly include food hygiene and safety risks, safety accidents risks, cash flow risk, financial risks, personnel risks, etc., while the external risks include competition risk, price risk and consumer risk.

\subsection{Food Hygiene and Safety Risks}

After COVID-19, consumers pay more attention to food safety and hygiene. For small catering companies, food hygiene and safety risks mainly come from the following aspects:

(1) Raw and auxiliary materials: "Raw and auxiliary materials" means any edible materials and substances that can be used for further processing and preparation into food (Luo et al., 2018). Due to scattered procurement demands and small procurement volume, most of small catering companies are lack of longterm and stable suppliers. The raw materials are usually not fresh or may contain harmful substances, such as the residual chemicals in vegetables, coliform bacteria in meat products and the total number of bacterial colonies in bean products exceeding the standard.

(2) Food packaging and tableware: Cheap and inferior packaging bags, packaging boxes, disposable bowls and chopsticks are usually used and tableware may be not clean due to non-standard disinfected. The outbreak of COVID-19 has demonstrated that the coronavirus has been frequently found on the packaging of imported frozen seafood and food packaging materials

(3) Food preservation and refrigeration method: Catering enterprises often need to prepare a large number of food raw materials and seasonings, and they are usually stored in the refrigerator. However, if refrigeration equipment is not able to achieve cooling effect due to old machinery or refrigerator frost, it may lead to shorter shelf life or accelerated deterioration of food. (Wang and Liang, 2017)

(4) Staff health: To save costs, some small catering companies do not apply for health certificates for chefs and waiters, nor do they have food hygiene managers.

(5) Processing environment: Kitchen processing environments for small catering companies are often poor. Haidilao, the famous hot pot restaurant chain, reportedly has poor kitchen hygiene and dirty mess.

(6) Processing: The personnel engaged in small catering industry mainly come from some farmers and laid-off workers in cities and towns. Operators and workers lack health and legal awareness. During food processing, some inedible debris may be mixed in food and not thoroughly cleaned. Mold, unclean, mixed foreign products may bring great hidden dangers to food safety.

\subsection{Safety Accident Risk}

Safety accident risk mainly come from the following aspects:

(1) Business facilities and service appliances: Most of Catering service facilities directly contact with customers, such as all kinds of electrical equipment, tables, chairs, tableware, etc. These could lead to accidents if they are broken down. For example, the solid alcohol drops or broken dish bowl may hurt the guests.

(2) Waiters' fault: The waiter's fault may result in personal damage, such as scalds caused when the waiter serves hot soup food.

(3) Fire: Most of electrical equipment and cookers are concentrated in the kitchen. If lack of fire safety management, it will cause a fire and threaten the safety of buildings, equipment and personnel.

\subsection{Financial Risks}

Small catering companies normally have no professional financial staff. Most of them only hired part-time financial staff. When dealing with financial problems, they often rely on subjective judgment, lack of rationality and foresight in decision-making. It is difficult to find the shortcomings in financial management, which may lead to financial risks such as cash flow risk and fund management risk. According to the Report on the Development Status and Trend of China's Catering companies, only $9 \%$ of the firms surveyed had liquidity that can afford for more than three months under the COVID-19, and 31\% of them can only afford 1-2 months. Many catering companies are shutting down because of broken cash flow (China Hospitality Association, 2020). 


\subsection{Competition Risk}

Small catering companies are in a weak position in the market competition. The international well-known catering enterprises, e.g., McDonald's and KFC, continue to pour into China market (Deng, 2014). The domestic large and medium-sized catering enterprises with large scale, strong financial strength and high management level, is also a strong competitor to small catering. Even the competition among small catering companies is very severe. On the same street, several shops offer similar catering. New restaurants, new dishes, new services and promotions can pose competitive risks. As a result of the epidemic, people eat out less often. Even if they go out to dinner, they are more like to go to large or medium-sized restaurants with better hygiene. For small catering companies, the situation is even worse.

\subsection{Price Risk}

Rent, raw material costs and staff wages account for $80 \%$ to $90 \%$ of the operating costs of small catering companies. Their working capital is raised mainly on their own and is more sensitive to these price fluctuations. During the epidemic, transportation and logistics were disrupted, the industrial chain was damaged and some food prices rose. The purchase of epidemic protection material, e.g., masks and disinfectant, also increases their operating costs.

\subsection{Human Resource Risk}

After the epidemic, the flow of people decreased and the shortage of labor became more acute. The departure of a chef or waiter, especially a chef, can lead to a serious staffing crisis. Some employees have poor sense of responsibility, low enthusiasm for work, and even frequent conflicts with management. The quality of personnel needs to be improved.

\section{Risk Countermeasures and Suggestions}

Risk prevention measures for small catering enterprises need to consider feasibility and economy. It should be as simple as possible and easy to operate. According to the various risks identified above, this paper puts forward the following risk countermeasures and suggestions.

\subsection{Risk Measures for Food Safety and Hygiene}

(1) Raw and auxiliary materials: Pay long-term attention to the freshness of raw materials. Select suppliers carefully and reasonably with the overall consideration of quality, price, lead time, delivery time, replenishment speed, service, etc. Establish long-term and stable cooperative relations with the suppliers. It is suggested that operators reduce the purchase of imported frozen foods and find the substitutes if necessary.

(2) Food packaging and tableware: Housekeeping tableware should be cleaned and disinfected daily in strict accordance with food hygiene regulations. For packaging used to imported frozen food, wipe the external packaging with a damp cloth or alcohol-containing paper after receiving the package and wash your hands after treatment. Clean and disinfect the surrounding environment. Waste residues should be packed separately.

(3) Food preservation and refrigeration: The best way to avoid this risk is to reduce the stock. The logistics nowadays is well developed and the replenishment speed can be achieved within one hour if well arranged. The operators should change the habit of hoarding and estimate the purchase quantity of the raw materials according to the sales data. Adjust the purchase plan to keep the suitable stocks or even zero stock because it can not only guarantee the quality of food material but reduce the purchase cost. On the other hand, it is still essential to arrange regular clean of the refrigerator, affix date mark, first-in, first-out, and regularly check the quality of food in stock.

(4) Staff health: The hygiene license should be hung in a conspicuous place. The health certificates should be issued for chefs and waiters. All the staff should test body temperature every day before work. Chefs and waiters should dress cleanly and neatly, wear hats, masks and gloves, and pay attention to personal hygiene (Zhu et al, 2021). All the staff should apply for vaccination.

(5) Processing environment: Clean the kitchen and dining places every day or after every meal according to the service provided. Cooked food, raw food and semi-finished products should be placed separately according to their relevant properties to prevent cross-contamination. Keep warehouse, refrigerator and other food storage areas clean and tidy. Dispose garbage and discarded food in a timely manner. 
(6) Processing: Develop simple and effective food processing procedures. Train employees and strengthen their awareness of food safe.

\subsection{Risk Measures for Safety Accidents}

(1) Safety of business facilities and service appliances: By identifying the hidden danger, a simple but effective safety checklist is suggested to make for regular inspection and maintenance of operation facilities and service appliances. The operators should assign a special person to carry out this checklist and ensure that the operation facilities are in a safe state.

(2) Waiters' fault: Skill and safety training is essential for the waiter's despite of the scale of the companies (Liu and Wang, 2020). Take appropriate incentive and punishment measures to improve the enthusiasm and initiative of employees.

(3) Fire: Allocate enough fire extinguishers and related firefighting facilities in accordance with firefighting regulations. Regularly check and maintain fire extinguishers and firefighting facilities, and update them in time if they are expired. Formulate the fire emergency plan and clarify the person in charge of firefighting. Organize the staff to drill regularly and improve the staff's ability to deal with emergencies. Add the fire inspection measures to safety checklist and make sure to check gas, stove and electrical appliances are turned off before closing.

\subsection{Financial Risk Measures}

Because of size constraints and cost considerations, it is not realistic for all small catering companies to hire full-time financial staff. The operators should enhance the awareness of financial risks and establish a simple and efficient financial risk control mechanism. There are some simple and effective accounting software which are specially developed for small catering companies. These software can manage not only the accounts including everyday income and expenditure, but also the cost of each dish, the stocks, the uploading of dishes, the orders, the real-time printing of sales receipts in the kitchen and bar, the operation data analyses, etc.

\subsection{Competitive Risk}

Explore the characteristics of the store and give full play to its own advantages. Pay attention to the opening information and promotion information of restaurants in the nearby business district. Adjust the publicity and promotion plan flexibly. Regularly launch new products, improve service awareness and management level. Establish and maintain the reputation of the store.

\subsection{Price Risk}

If the cost of decoration is high in the early stage, it is suggested to sign a long-term contract with the landlord for more than three years so as to avoid the price fluctuation of renting contract once a year. In purchasing raw materials, long-term cooperation agreements should be signed with the suppliers. The price fluctuation of raw materials should be paid attention to. Fresh electricity suppliers should be considered as an alternative supplier.

\subsection{Human Resource Risk Measures}

Appropriate incentive measures are taken to provide employees with enthusiasm and stability. Judging from the implementation effect of Haidilao, employee ownership is a very effective measure which is also the case for small catering companies. Only by linking the service performance of chefs and waiters with their wages and welfare can they fully mobilize their sense of responsibility and enthusiasm, and all the risk measures mentioned above can be effectively implemented.

\section{Conclusions}

In the catering enterprises, small catering companies occupies a large proportion especially in the country's various laws prohibiting waste. Small catering companies is therefore ushered in a good time for development. However, compared with large and medium-sized enterprises, the small catering companies lacks corresponding management in terms of financial resources, material resources and manpower. Therefore, the defects of the anti-risk ability of the small catering companies will soon be exposed when confronting some risks. 
With the improvement of living standards and educational quality, more and more operators of small catering companies have bachelor's degrees and even master's degrees. Their attention to operation and management is also increasing. However, the attention to risk management is still relatively deficient. In order to grow healthily and sustainably, small catering companies' operators should establish the correct risk management concept and take measures actively to the various risks identified. The concept of risk management, as an enterprise's overall cognition of risk, requires employees in all positions to have a correct view of it and be able to timely discover, correctly evaluate and reasonably respond to risks on the whole. This paper puts forward the risk countermeasure, in fact, the overall promotion of management. Operators of small catering companies should not only pay attention to risk management by himself, but also help employees to establish risk management consciousness and inform employees the corresponding consequences who may face in the daily business activities by training. Only in this way can employees have a real sense of crisis and risk awareness, actively discover risks in daily operations, and actively report the existing risks so as to avoid or reduce the adverse consequences caused by the occurrence of risks and remain invincible in the fierce competition.

\section{References}

1. China Hospitality Association (2020). Report on the Development Status and Trend of China's Catering Industry under COVID-19. Beijing: China Hospitality Association.

2. Deng, B. Y. (2014). Study on the Problems and Countermeasures of the Development of China's Small and Mediumsized Catering Enterprises. Journal of Jiyuan Vocational and Technical College, 13(2): 64-66.

3. Liu, S., \& Wang, C. F. (2020). Impact of COVID-19 on Small and Medium-sized Catering Enterprises in China and Countermeasures. China Business Review, 19: 29-31.

4. Luo, X., He, J. S., \& Huang, W. (2018). Summary of Risk Research in Catering Hygiene Field. Modern Management, 8(4): $380-386$

5. Wang, X. Y., \& Liang, Y. X. (2017). Food Safety Risk Identification and Prevention and Control in Catering Industry. Information Record Materials, 18(6): 178-179.

6. Zhu, Y. Y., Zheng, Y. T., \& Fu, Y. R. (2021). Research on Risk Management of Catering Enterprises under COVID-19. Modern Business, 4: 6-8. 